small upper one of $\frac{1}{2} \mathrm{lb}$. simply serves to keep the chain taut. The up-and-down movement of the main weight operates a small rheostat controlling the speed of the winding motor, so that as the weight rises it introduces more resistance, thus slowing the motor until a balance is obtained. The weight then floats almost stationary, and the motor winds at the

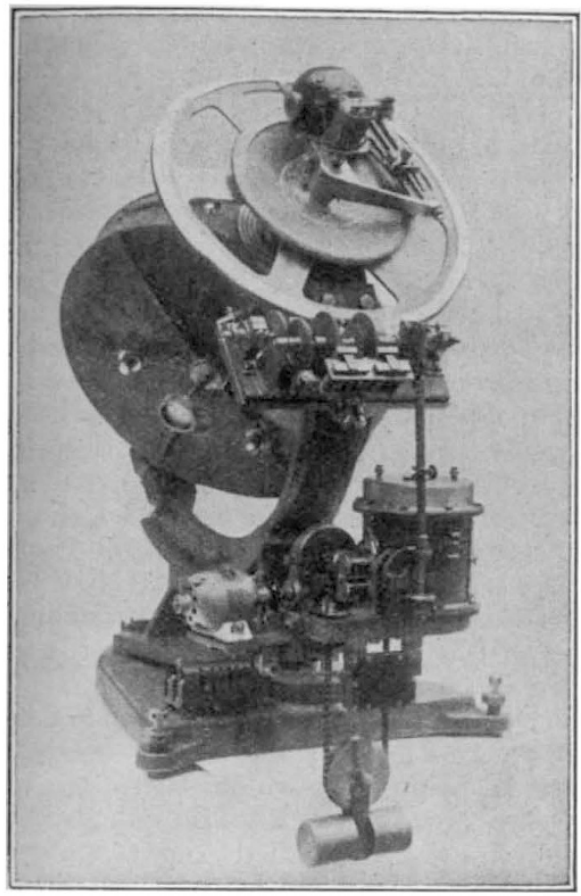

FIG. 4.-Arrangement of clock, gearplate, and driving circle.

same rate as the clock unwinds. A second rheostat is also fitted, so that the motor speed may be approximately adjusted when the instrument is installed.

When the motor is switched off, the main weight continues to fall and the little weight rises until ultimately it will reach the top of its travel and stop abruptly. In order to prevent damage, due to the great inertia of the governor, a ratchet is incorporated in the clock sprocket to allow the governor to run on freely.

The motor armature was carefully balanced by the makers, and as an extra precaution against vibration, the whole motor is mounted on thick pads of Sorbo rubber and the drive is transmitted through a thin flexible coupling.

To ensure the utmost accuracy in the rate of the mirror, the speed is further controlled by a pendulum, using the 'Russell' type of control. Just before the main spindle leaves the clock, a friction clutch is inserted that will slip if anything obstructs the free movement of the spindle. Round the edge of this clutch is a series of six pins which travel past at the rate of one per second, and a steel pawl is so placed that it catches one of these pins and holds it stationary until the pawl is drawn clear by an electro-magnet operated by a pendulum of an accurate clock. In this way the motion is held momentarily until released by the controlling pendulum at the end of each second. It is, of course, necessary to run the colostat clock a trifle fast in order that this control should be effective. The arrangement of these various mechanisms is clearly shown in Fig. 4.

\section{The Electric Quick Motron.}

This is a great convenience in setting the mirror from a distance into the correct position at the commencement of observation. To avoid having to unmesh the driving worm, the main wormwheel is loose on the mirror shaft, but the drive is transmitted through a small auxiliary worm and wormwheel which can be turned by an electric motor also mounted on the spindle. In the ordinary way the whole arrangement, including its motor, turns with the mirror once in two days; but when the quick motion is required, this auxiliary motor is started up and the mirror shaft then rotates, independently of the main wormwheel, at the rate of one turn in about two minutes. The motor is, of course, reversible from the distant control switch, and the current is led to it through four slip-rings and wipers. The worm drive for this quick motion can be thrown out of gear when it is desired to turn the mirror by hand.

\title{
The Suez Canal in Relation to the Marine Faunas of the Mediterranean and Red Seas. ${ }^{1}$
}

$\mathrm{T}$ HE marine faunas of the Mediterranean and Red Seas differed so widely from one another before the opening of the Suez Canal that in many groups, if a species was found in one sea, it was almost certain that it did not occur in the other. Since then there have been a few Red Sea crustaceans found all over the Mediterranean, and a swimming crab is being commercially fished along the North Egyptian coast, where also the Red Sea pearl oyster is common. The intermingling of the two faunas being clearly an object of great interest, the Royal Society provided the requisite funds for

1 Cambridge Expedition to the Suez Canal, 1924. (London: Trans. actions of the Zoological Society, 1926. Part I.

No. 3042, VoL. 121] the Cambridge Expedition, the first reports of which are now before us. The leader of the expedition was Mr. (now Prof.) H. Munro Fox, who for several summer vacations had worked at the Suez end of the canal, and with him were associated Mr. Robert Gurney, Mr. V. C. Robinson, and Mr. D. N. Twist. Help was also given by the directors of the Orient Line, and the expedition received an unstinted, generous, and most practical welcome from the Suez Canal Company and the Egyptian Government.

Along the line of the Suez Canal are limestones of Cretaceous and early Eocene ages, the arm of the Mediterranean that extended down what is now the Red Sea only coming into existence in the 
Miocene, when the whole area was peopled from the Mediterranean. In the Middle Pliocene a connexion was formed that allowed an invasion of Indian Ocean animals. How and when exactly the Isthmus of Suez was built is not known, but in the Pleistocene there was a freshwater lake over part of what is now the Isthmus, this containing a series of molluscs of species many still living in the Upper Nile.

It was at this period that the fauna of the Gulf of Suez assumed its almost completely Indian Ocean facies, and the fact that it did so is remarkable enough and by itself quite sufficient to make desirable the present study. The Bitter Lakes were once an arm of the Red Sea, the top of which periodically was isolated and dried up, giving alternate layers of salt and sand. The Pharaohs dug a canal connecting the Bitter Lakes and so the Gulf of Suez to the Nile, and this continued more or less open until the eighth century. It was not a traffic route, as the terminal ports were in Egypt itself, and so differs scientifically from the present canal, the connexion being through a long stretch of fresh water, without unbroken journeys by means of which animals attached to ships could pass from one to another area.

The scientific results of the expedition can only appear gradually as groups of animals are worked out. The Bitter Lakes have increased in depth by nearly three metres, owing to salt solution, since the canal was opened, but the maximum density of their surface waters is only 1037bottom $1042=$ salinity $1 \cdot 053$-as compared with average densities of about 1027 and 1031 in the Port Said and Suez Roads respectively. At Lake Timsah the density varies from 1006 to 1036 , and in places fresh water overlies the sea water, each containing its own organisms. The fauna and flora of the canal are poor, probably due to dredging and the churning up of the water by ships, since piles and mooring buoys show abundant growths.
The bottom of the Bitter Lakes is covered, over the salt bed, by black mud devoid of macroscopic life, but the shore regions show a fauna and flora richer in numbers of species and individuals than similar areas at either end of the canal. Rather unexpectedly, there is no sign of stunting or deformity except in the Foraminifera, some organisms showing markedly increased size.

Clearly, to-day salinity is no barrier to migration, to the swimming, crawling, or carrying of adult organisms between our seas, but it may have been in the past, since the density of the Bitter Lakes in 1869 was 1123 , - and it may still be to forms only distributable by delicate larvæ or eggs peculiarly subject to changes of osmotic pressure. The amount of hindrance by reason of high temperatures is small, but more data are required. Tugs, coal barges, etc., dirtied by organic growth, are frequently changed over from the terminal ports and are helpful. Currents deduced by Prof. Fox from density observations show that Bitter Lake water, as affected by Red Sea tides, is carried from October to July nearly to Port Said, and Mediterranean water to beyond Lake Timsah in August and September. Of 12 groups of organisms there are found in the Canal 83 Mediterranean and 234 Red Sea species, but we must await further lists and analyse these into areas, while the breeding dates are all important in respect to currents.

Scientifically, periodic investigations of the Suez Canal flora and fauna should have been made in the past in respect to which there are no data such as are now required. The expedition under discussion has collected all there were and given a definite basis upon which future science can work. It cannot, however, be deemed to have completed its rask rutil its members pay a further visit to the canal to study the conditions from July to September, the months of heat and of northerly currents, one member in advance to collect data on breeding in the previous quarter.

\section{Obituary.}

Prof. J. Fibiger.

$I^{\mathrm{T}}$ $T$ is a tribute to the perennial fascination of the cancer problem that Johannes Fibiger, whose sudden and unexpected death on Jan. 30, at the age of sixty years, is deplored by the medical profession of the world, only became known to the wider medical and lay public through his contribution to its solution. It is eloquent of the importance and value of his work that his death has evoked world-wide tributes to his memory.

Fibiger was appointed professor of pathology in the University of Copenhagen in 1900, and until 1913 was known only to pathologists through his careful work on tuberculosis. In 1913 the accidental discovery of cancer of the stomach in rats associated with the presence of nematode worms in the actual substance of the growth, started him on the intricate and arduous investigation which led to the discovery of the first successful method of experimental cancer production. The magnitude of this achievement is seen in the great expansion to which it has led, in the study of neoplastic growth. The tar cancer work of Yamagiwa, Itchikawa, and Tsutsui was directly inspired by it, and Fibiger himself was quick to discern the experimental advantages of the chemical method, his own researches in the subject doing much to establish it in the forefront of the means at our disposal for probing the caustive factors in malignant disease. Even more directly the offspring of Fibiger's genial discovery, is the method of sarcoma induction in the liver of the rat by the larvæ of Tcenia crassicollis, worked out by Bullock and Curtiss. The production in animals of X-ray, paraffin, and arsenic cancer easily followed as an extension of the avenues of attack opened by Fibiger.

The substitution of exact experiment in the place of more or less nebulous speculation, to which the discussion of cancer etiology was previously restricted, is now acknowledged by all serious students of the cancer problem as the most precious 